\title{
Exploring Coping Strategies of Transfer Students Joining Universities from Colleges
}

\author{
Monika Foster \\ University of Sunderland, United Kingdom \\ Timothy Mulroy \\ Sheffield Hallam University, United Kingdom \\ Mark Carver \\ University of St Andrews, United Kingdom
}

\begin{abstract}
Students transitioning from colleges to universities in the United Kingdom (UK) into the second or third year of an undergraduate programme must quickly adapt to a new learning environment and new expectations. The process of transition includes intense demands on their time and, for many, a requirement to commute. The consequence can be a limited university experience compared to those who began their studies in the traditional first year. With the increase in the numbers of transfer students studying at universities in the UK, this study was set up to explore the challenges of transition at two universities using an online survey and focus groups. Results show that transfer students cope with their transition to university in multiple ways, categorised into the following themes: learning expectations, peer support, online engagement, cue-seeking and efficiency. By supporting the use of these coping strategies, universities can facilitate a better student experience and enhance student success.
\end{abstract}

Keywords: Transfer students; transition; coping strategies; engagement.

\section{Introduction}

For any student making the transition to higher education, retention and success are predicated on building a sense of belonging among peer groups (Thomas, 2012). There have been significant changes in the profile of students recruited by universities in the UK (Thomas, 2020) due to the widening participation agenda. This agenda has been in place since 1997 (Kennedy, 1997) and has aimed to address discrepancies in the take-up of higher education opportunities between different under-represented groups of students (Connell-Smith, \& Hubble, 2018). As universities continue to attract a more diverse student body, including professional and mature students, many already in employment, there is a need to better understand their transition experience, (Fernandes et al., 2017; Gale \& Parker, 2014). This study focused on the experience of students making the challenging transition from a local college study environment to entering a university part-way through the degree programme. As noted by Curtis (2009), these students can be described as 'transfer students' to distinguish them from those traditional students who enter the university in year one of a degree programme. Transfer students were asked their views on the coping strategies they employed to succeed at university, if the support offered by both academic and professional services staff met their needs, and if this support was effective.

Except where otherwise noted, content in this journal is licensed under a Creative Commons Attribution 4.0 International Licence. As an open access journal, articles are free to use with proper attribution. ISSN: 2205-0795 


\section{Coping Strategies of Transfer Students}

Research on the transition to university has found that the initial transition experience has a significant impact on both student satisfaction and, ultimately, their success (James et al., 2009). A range of complex issues affect students in their transition to university life including, personal, social, and academic concerns (Foster, 2008; Nelson et al., 2012) which impact upon their ability to manage their own experience of change (Gale \& Parker, 2014). From research on student experiences of transition (Denovan \& Macaskill, 2013; Fernandes et al., 2017; Gale \& Parker, 2014), this study identified the different ways that students coped with the move to studying at university. The themes identified were; managing learning expectations, facilitating peer support, online engagement, cueseeking and efficiency.

For those students traditionally entering a programme in year one, there are usually induction events and an assessment design that is low-stakes, with plenty of opportunity for feedback. Joining the later years of a programme already in-progress means that transfer students immediately enter the assessment environment as it becomes high-stakes, each module grade contributing to their final degree classification. At the same time, they may also be managing other responsibilities, such as part-time or even full-time employment (Kember, 1999), putting transfer students at increased risk of feeling disengaged from their university experience (Cheung et al., 2020). Without the same institutional safety net as that provided for year one students, transfer students have been found to develop a range of coping strategies including approaching learning in a more surface, instrumental way, or drawing strength from a sense of group belonging (Sanchez-Gelabert et al., 2017).

Such strategies employed by transfer students relate closely to the classic distinction between surface and deep approaches to learning (Marton \& Saljo, 2005). When students feel that they have the time and that learning is worthwhile, they will take deep approaches such as reading widely and discussing work with peers. With time pressures or where an assessment seems to reward basic recall, students will take surface approaches to learning such as memorising key facts for short-term recall or narrowly focusing on what is assessed. These surface approaches can also involve students reverting to learning strategies that have been successful in study at lower levels such as school or college, giving a sense of familiarity and comfort but limiting the extent to which students engage with the more in-depth learning desirable at undergraduate level. More experienced students may make explicit choices - the 'strategic approach to learning' - as they recognise different study and assessment needs and where their time can be most efficiently spent. For transfer students, however, they may not have the time to acquire what a Bourdieusian might call tacit "rules of the game" (Roberts \& Sarangi, 2001, p. 176) which allow them to make such decisions effectively. Analysis of student expectations and aspirations (Longden, 2006; Smith \& Hopkins, 2005) indicate that many students have difficulty predicting their student experience and understanding what the university expects of them. For transfer students, who have less time to assimilate into the university, their focus on cue-seeking and efficiency is recognised as key ingredients in succeeding at university.

Transfer students may also have different experiences of group identity, feeling unlike what they expect a full-time student might feel (Cheung et al., 2020). The importance of feeling part of a group extends beyond social support or a sense of community, although it is partly this. Group belonging can be linked with social theories of learning in which informal or tacit learning is embodied (Wenger et al., 2002). This is especially important in professional and higher education in which knowledge can often be tacit, such that part of a student's education should be to learn what is valued in their profession and how to self-evaluate and improve their work to meet such standards (Boud \& Molloy, 2013; Sadler, 2010). Students making the transfer into a new university identity shape their own educational experience through peer groups and use of online support to create an excellent teaching and learning environment within a connected and cohesive higher education community (Thomas \& Jones, 2017). To enhance student success, institutions have a key role to facilitate transfer student engagement, support and belonging (Kift et al., 2010).

\section{Study Design}

To explore how transfer students approach their studies across disciplines, the five themes identified in the literature review including learning expectations, peer support, online engagement, cue-seeking and efficiency were used in the mixed method study with transfer students in Engineering and Business programmes at two universities. These two subject disciplines have consistently attracted large numbers of transfer students, due to the high volume of students on vocational and applied courses in colleges (Brown et al., 1999). We were able to identify statistically significant numbers of these students - mature, part-time, in-work - because both universities are post-92 institutions, created in part as a commitment to the widening participation 
agenda in the UK. All the students in the study had transferred into the university mid-programme from a local Further Education (FE) college and were asked about the different ways they managed their studies.

The study was designed as sequential mixed-methods, generating rich qualitative and quantitative data through an online survey and then built on by the qualitative data through discussion of the earlier data through in-person focus groups. Participants were invited to anonymously complete online surveys created using Google Forms. From a possible 138 students, 80 completed the survey (response rate 58\%), 14 of whom later participated in three focus groups. The survey form concluded with an opt-in choice for anyone willing to participate in focus groups, which were led by a senior academic with whom the students were familiar. Students were assured throughout that participation was voluntary, their data would be anonymous, and that they could withdraw at any point before data anonymisation without needing to give a reason and with no detriment. Focus groups were audio-recorded, then transcribed and bottom-up coded by a researcher from a third university. This same researcher also conducted a more in-depth analysis of the online survey using inferential statistics, as discussed below, to add an iterative element of data analysis to the sequential data collection. Survey and focus group questions are presented in the appendices.

Questions were based on the five emerging themes from the literature to address the broad research topic of how students respond to the challenge of transition and then how they evaluate the success of their strategies and responses. This included asking open questions about what went well and what could be improved in any induction as well as more general opportunities to comment on their experience. This general questioning was supplemented with closed questions chosen to focus more specifically on previously reported observations of what students and lecturers described as important in supporting student transition success. The survey also asked about common motivations to study or why a particular programme or university was chosen to explore the idea that transfer students may have different study intentions than traditional students, and so measure their success in different ways.

The focus group questions explored some of the issues that course tutors had mentioned as possible factors, or that had been identified as noticeable differences between the college and university environments. Questions asked towards the end of the focus groups invited recommendations for improvements that the universities could make. Students taking part in the survey were broadly representative of transfer students on their programmes of study, with gender and age balanced across the range, with the majority of students being under 25 and female.

Comparisons based on the two programmes (and so, by extension, university), age ranges, and genders were made using independent t-tests and ANOVA for responses to the Likert-type items. Simple descriptive statistics from the qualitative codes were also used for open and nominal responses. After determining that there were no statistically significant differences based on age, gender, or university of study, responses were treated as coming from a comparable sample and all 80 responses were analysed together.

Qualitative data from the open response questions on the survey was then later combined with the focus group transcripts. Coding was used to classify responses by descriptive themes, keeping as close as possible to the original phrasing from the students (Saldaña, 2013). This resulted in five themes, which were then compared with the key themes arising from the literature on the features of successful student transition.

\section{Results}

The results from the survey were combined with the focus groups results and represented in five themes based on the literature on coping strategies of transfer students. The survey summary of responses to each of the Likert-type items is shown in the chart below, with correlation analysis and discussion of responses to the other survey items incorporated with the qualitative data analysis in the following sub-sections.

Overall the results from the survey show that students have a very different online relationship with each other than they do their institution. Limited engagement with staff and the broader university community was similarly contrasted against a higher than expected collaboration with peers. Looking at this through the lens of efficiency highlights how students seemed to be more positive of tutors who were not regarded as 'the university', but rather became quasi members of students' informal communities through being more available and helpful. 


\section{Figure 1}

Responses to Likert-Type Items

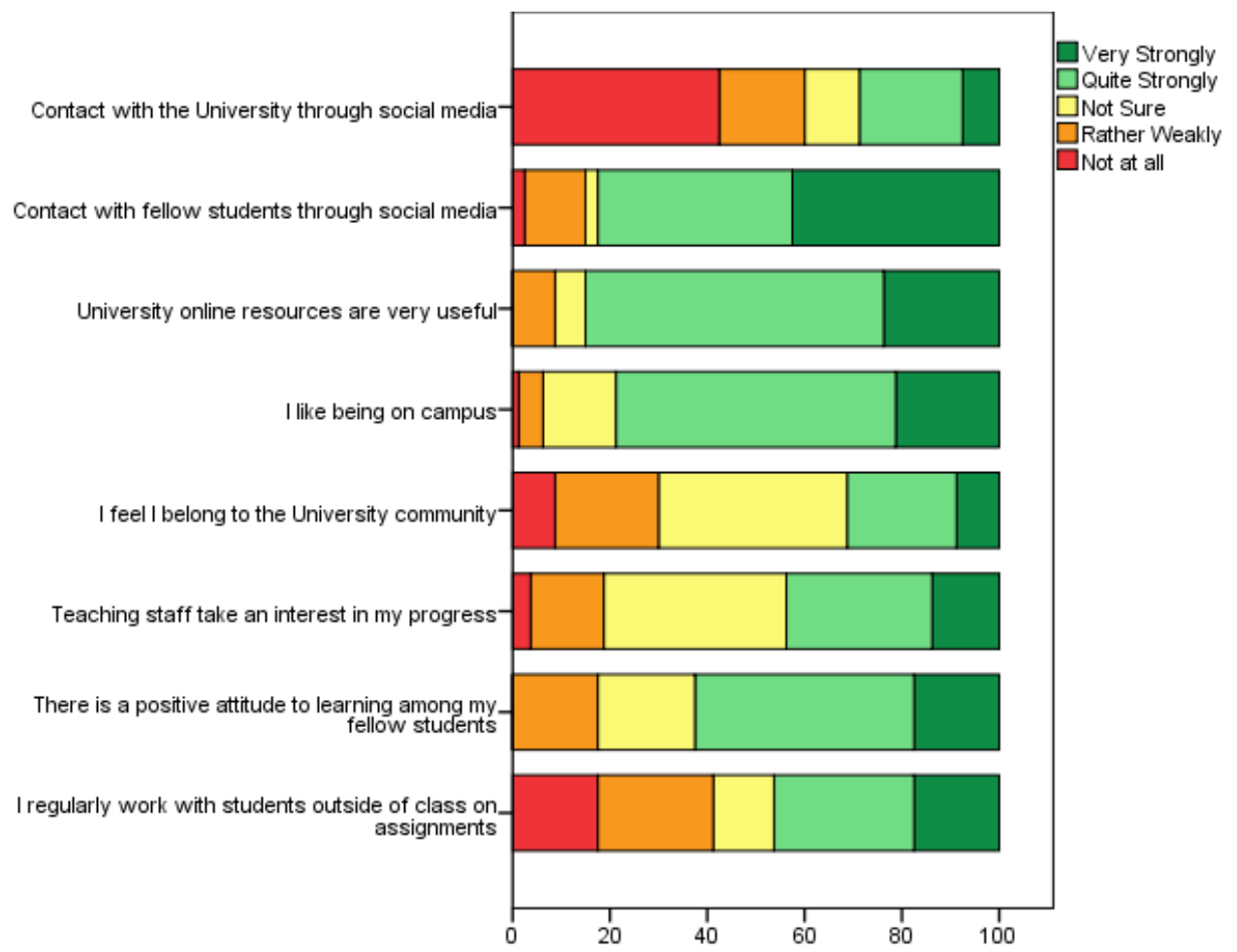

The above survey results were further enriched by the qualitative data arranged in the five themes arising from the literature: learning expectations, peer support, online engagement, cue-sSeeking and efficiency. Each theme is briefly discussed below and illustrated with quotations from the students to bring to life their lived experience.

\section{Learning Expectations}

Of the 109 different reasons given for choosing to take a degree, the majority (55\%) described better job prospects with similar sentiment in improved salary as a motivation (24\%). Other motivations included gaining an enhanced qualification (42\%) and a new experience (17\%). Close links to a profession were also discussed in the focus groups, with discussion of their learning at university being more "real" or "proper" than at college. This included a more focused curriculum, authentic assessments, and higher demands for independent learning without the "safety net" of college. One notable discussion around the need for mathematical ability exemplified this well as students discussed how college had failed to prepare them for the demands of the university programme, rather than questioning whether they needed such skills. Students seemed to trust the relevance of the programme and deem their participation as worthwhile, even while complaining about the burden of assessment and dominance of essays as an assessment strategy. The strong link between university study and the professions seemed to motivate students to work hard and align their personal goals with those of their programme. Related to this was an acceptance of the university expectation of independent learning, where it might be expected that students felt neglected when comparing their recent college-based experience. One student described this shift in expectations:

We all go on courses with work and, frankly, when I go on a course with work I expect to be taught the subject. I'm having to reframe that here slightly in that I'm here to learn it with you a bit and a bit myself, but that's really alien to us. We've spent all our working careers being sent on tens of courses where it's 'you will be taught this' and if you're not taught it then you've got every right to complain about it...you're giving us the learning environment, not the knowledge 
This was intriguing since the main reason given for choosing the university was the specific programme on offer (36\%), which could have implied that students were seeking to develop specific skills or gain specific knowledge. Instead, it seems that students were happy with the different learning expectations compared with college or work courses.

\section{Peer Support}

The discussion of learning style also related to how students identified as a group of transfer students. One focus group discussed how they were content to be labelled as transfer students as the group gave them support. As one student put it, "If we're helping each other, does it matter what the label says?" Some students also emphasised their professional experience as part of their group identity, so rather than seeing themselves as a group lacking experience of university study they saw themselves as a group with the advantage of work experience. This was neatly summarised as "we're not disadvantaged; we just don't know how it [university] works".

Peer support was a surprising story within these results, particularly in how students created informal groups online. Many students worked together outside of class despite often not living near each other or having dedicated study time. The responses to the Likert-type questions show a strong contrast in how students engaged with their peers and with their university. There was minimal contact with the university through social media and a lack of feeling part of the university community, but extensive contact with peers through social media and generally positive views of how other students approached learning and enjoyment of time on campus. Students were reporting engaging with peers in a very different way from how they engaged with the university. Their online interaction was similarly high among themselves but did not generally involve the university beyond accessing resources.

Students also gave each other practical information such as where to find online resources, navigate around campus, how to submit assignments, study tips for managing their time, and finding study spaces off campus such as through the SCONUL scheme. This also helped to overcome communication breakdown for those who did not find out about key dates, with a substantial minority of students missing induction days or only finding out through a colleague or WhatsApp group. Peer support was also important for reassurance when students were unsure about their progress or if they were meeting expectations. When they might otherwise have felt overwhelmed, it was reassuring that:

None of us seem to know if we're on track or not, we're all assuming we are because we talk with each other therefore if the mob is in that position then everyone must be in that position because everyone can't fail...it's like survival of the masses, a herd of wildebeest where a few outliers get picked off by the lions.

This simile suggested a group of similar achievers, suggesting that it was important for students to feel they were among likeminded and similarly able peers. There also seemed to be a sense of risk uniting the group so that nobody deviated too far from the norm. This is a marked contrast with discussions of the college "safety net" where tutors ensured survival, suggesting that peer support was much more important in the university environment.

\section{Online Engagement}

Students clearly distinguished between social media contact with peers and with the university. Some students wanted to keep their social media separate from their studies, particularly Facebook or places where they shared photos and their private lives. Others were happy to engage with Facebook groups but did not want to be friends with university pages. In part, this was explained as a desire to avoid "spamming", a similar issue raised with university email accounts where some students stopped checking their emails because they received too many irrelevant emails and adverts for social events. There was greater comfort with WhatsApp since students could make these groups for themselves and have sub-groups. On these terms, many students thought it would be helpful to have some WhatsApp groups with their tutors as members so that advice and information could be quality controlled. This echoes similar advice in social media marketing that companies must give customers control over their communications (Martin \& Murphy, 2017) and that engagement with personalised content is only successful when customers feel in control of their data (Tucker, 2014).

Students were also keen for more online engagement, including how-to videos and knowing that teleconferencing was available as part of normal contact with tutors rather than being a special arrangement they would have to make. There was also some support for more formal forums than WhatsApp groups where peers from the year above could offer guidance, although this 
was always discussed along with the need for tutors to make sure that such advice was still relevant. In one specific case this seemed due to referencing guidelines changing from one year to the next and some information not being updated, but there was also a general sense that students were only fully reassured when a tutor gave their approval.

\section{Cue-Seeking}

In addition to giving advice to each other in peer groups, students described what the approaches to learning literature would call cue-seeking behaviour. Students spent a lot of time trying to figure out what was needed for an assessment. This was seen as varying from tutor to tutor and being "a gamble" to know what was required. Students were very keen to have exemplars of good work, though again were wanting this from each tutor rather than trusting that generic criteria would apply in all cases. In this respect, traditional entry students were thought to "get their first year free" to figure out what is required, and some transfer students discussed how they may get lower marks while they figure out new expectations or have to readjust to a new tutor. Students were particularly concerned that they had not written at the required level before, and so were unprepared by their college course. Concerns about practicalities of layout and referencing were most common, with general "writing expectations" also needing to be figured out as was the amount of wider reading required. Again, this seemed rather inefficient with "each lecturer doing their own thing" as regards blackboard layout or assessment expectations. This was compounded by inconsistencies between college and university, so the only way students felt that they got reliable information was directly from tutors or as assessment feedback.

Descriptions of cue-seeking behaviour may have been less candid since focus groups were facilitated by programme tutors, but the discussions still gave a sense that cue-seeking was not about taking short-cuts or gaining an edge. Instead, students saw cue-seeking as necessary due to the inconsistency and unreliability of information coming from the university. Each tutor needed to be figured out, even to the level of how they liked essays presented on the page or their take on what were meant to be universal referencing guides. Students were not cue-seeking in opposition to faculty but seemed united with a select few trusted tutors in opposition to the inefficient and idiosyncratic body known as 'The University'.

\section{Efficiency}

Efficiency emerged as the dominant theme in the first-cycle coding of the focus group interviews. It was the surprising way that students talked about efficiency that prompted the second-cycle coding to look specifically at students' approaches to learning and group formation rather than just their experience of induction and transition. A common concern related to efficiency was students making good use of their days away from work. Avoiding blocks of 'empty time' in a day or isolated lectures was pragmatic not just in saving commuting time, but in justifying a block of time away from other commitments. Even social events need to be pre-planned and made worthwhile: social events at 6 p.m. are inconvenient when classes end at 4 p.m. Making small organisational improvements can benefit all students but might have even more impact on students at risk of feeling separate from their peers.

We also found that students often felt overwhelmed by emails to their university address and simply stop checking them, indicating that the only reliable source of important information comes through WhatsApp groups from those peers who still pick up their emails or receive direct emails from a tutor to a personal account. This creates problems when institutions have policies of only contacting students through their university email, but points to a more fundamental issue that emails need to be limited and coordinated. Reducing emails to students and finding ways to highlight priority messages would help to keep this important channel of communication open, as might starting a closed Facebook/social media group with clear roles for participation.

Poor information flow from both colleges and universities prompted discussion of inefficiencies. Some students were delayed from registering because their certificates were not ready, while others did not receive information in a timely enough manner to make arrangements for their other commitments. In terms of identity, students are largely comfortable with slight outsider status. They study off-campus, finding course-mates who live locally and can meet in coffee shops or local libraries. They do as much as possible in advance and online. They expect university administrators to respect their time as professionals, so they will simply short-cut to a colleague or academic tutor if they feel the university processes are inefficient. One student's experience gives a good example of such short-cutting being necessary: 
They [administrators] said they'd contact you closer to the time. It got to August/September time and nothing came through. I'd sent multiple emails saying 'what's happening, when do we enrol?' You just got emails back saying 'Don't worry about it, we'll get in contact when the time is right'. When it got to the week before we're meant to start I rang up and said I need to speak to somebody. They put me through to [tutor] and she sorted it that day. Within an hour or so we'd got a date when to start...if I hadn't have pushed, I'd still be waiting at home.

This example set the tone of students needing to speak to their tutors to get an efficient response on what should have been routine matters. Other students who did not get to speak to a tutor found out too late: 'I asked 'when's the induction?' and they said 'yesterday'." Others found out from colleagues that it was the next day, received the wrong information and so came on the wrong day, while one particularly patient student phoned to find out that he had missed the first two weeks of the programme. There was obviously much discussion of being irritated by these inefficiencies, but it was striking that students took a pragmatic approach in their recommendations. They included asking for generic information pages they could access before results were confirmed, a list of key dates, or even a checklist of what information they should have by when, so that they knew when they needed to chase up administrators. Some WhatsApp groups had already formed by this stage, so the scraps of information managed to flow despite some central problems.

Efficiency was strongly linked with personalisation. Students wanted to have clear, specific guidance on how to access the electronic resources they would need. Ideally, these would be videos made by their tutor. Similarly, rather than a general induction, they appreciated meeting tutors, and many stated a preference for module-level mini-inductions throughout the year rather than a front-loaded and more generic induction. There were some potential frustrations for tutors in this, with complaints that students did not go to the induction because they did not think it was relevant often followed by complaints that they did not know about something that was covered in the induction. However, the pressure of competing demands on these students may put this in better context. Some students described 16-hour days to travel onto campus, while plenty more sacrificed social and personal lives to meet study and work commitments of 60 or 70 hours per week. Deadline bunching meant having to work as efficiently as possible, so attending a two-week programme and waiting to sift the key information was wasting precious time. One student described how "you've got to be running at 99\% efficiency" to manage all these demands. This stood out in the analysis as explaining why cue-seeking was not about taking short-cuts but was a necessary response to overwhelming demands and frustrating inefficiencies inherent in a system that assumes students have the luxury of full-time study. Unfortunately, this puts a greater burden on university tutors to take on a role similar to a college tutor in managing many of the practicalities of students' learning. However, it is at least reassuring to think that students do so not because they want their "safety net" back. These students were agreed on the importance of independent learning and can be seen simply as cue-seeking to mitigate against barriers to being able to give this the time it deserves.

\section{Discussion: Willing Outsiders?}

The students in this study seem to be forming small groups within their broader identity as transfer students, often based on chance aspects such as making friends during induction or living near to each other. They seem to have largely positive regard for the students already on the programme they were joining, but seem less connected with them and do not regard them as having had the ideal university experience or something which should be emulated. Rather, transfer students gain support from other transfer students in the year above whose experience more closely resembles their own. These students also retain a professional identity, but still see university study as something special and distinct from their professional learning experiences to date. They are happy to go along with the goals of the programme, and do not seem to question the demands made of them. This makes sense since they mainly chose their university study with a specific programme and career progression goal in mind. These students generally worked as hard as they could and sacrificed a great deal in their personal lives to give their university study the time it deserved. Grades were not so much about personal progress as a way of finding reassurance that they were doing enough. This seems a crucial distinction, absent in how student groups have previously been described. It was discussed how the 'herd mentality' seemed to disappear as students became individuals rather than groups, but it seems there is still a desire for students to reference their behaviour to their peers in order to understand what is expected of them and how hard they should be working.

Efficiency is key to the identity of this group. This is not to avoid the need to take deep approaches to learning or to carve out time for other interests but is an entirely rational response to the perception that the university is an inefficient and idiosyncratic place to work and study. This puts a burden on tutors to be the final arbiter in what should be routine information from administration or disseminated through online information. Peers can offer tips and support to mitigate such inefficiencies, but 
the reliance on key tutors for all information risks information bottlenecks and over-stretching academic staff. The ideal solution would be for the university to be a more efficient place with clearer communications, but online peer support has been shown to help achieve this, without needing to wait for more fundamental institutional reforms. Students are self-organising using social media that they control, creating groups which the university may not even know about. Tutors signalling their openness to engaging with students on their terms might find themselves invited to join such groups, potentially adding greater efficiency and reliability to the information exchanged online. There is already some communication from one cohort to the next, so finding ways to maintain these groups so that they mature rather than respawn could further support students in feeling that they are treading a familiar path. Such informal groups could add to the emphasis on programme design enabling "coherence, continuity and connectedness" in learning across a programme (Nisbet et al., 2005). A simple recommendation could be to signal explicitly to students if expectations or tasks have changed from one year to the next, helping to reduce uncertainty as modules or materials are revised.

Within the limits of these two samples and reassured by the similarities between what were intended to be contrasting groups, there seems to be evidence of an increasingly collaborative community among students. Transfer students are willing to take charge of their own university experience and will use social media and online tools to collaborate if official communications are deemed insufficient.

\section{Recommendations}

The similar experiences of what were intended to be contrasting groups of students suggest that induction needs are more similar than they are different between different subject groups and could potentially open opportunities for cross-subject induction events, helping to consolidate much-needed resources. Ongoing support that engages with students' informal and online communities is much more efficient from students' perspectives, which makes it more effective and engaging. Frontloaded, formal induction may be more efficient for the university, but is not recommended. Instead, students may see the use of ongoing WhatsApp groups as a key support in their learning, by improving the efficiency of communication with students, as a viable alternative. This could easily be extended to include mentors and/or tutors in WhatsApp groups. The study has also highlighted the importance of meeting students' expectations of professionalism so that their time on campus is well-spent, communications are clear, and that students can make efficient use of their university experience. Commonality in the transition experience also suggests that stimulating informal peer groups, perhaps even across different subject areas, could help offer additional support as students adapt to their new environment, and that this need not be limited to students' subject areas.

As universities strive to make themselves more relevant to a diverse pool of students, with degree apprenticeships and short courses gaining ground as well as further ways to engage mature students, this study suggests a new type of student professionalism. This approach positions faculty and students closer together rather than in opposition, adopting a boundarycrossing role as invited members of informal online spaces. From the feedback in our surveys and focus groups, it has been shown that student-led fora and WhatsApp groups can help bridge the formal and informal support and address student progression and attainment for transfer students. Part of the reason here could be age - these transfer students already have a professional social media identity and feel comfortable engaging with lecturers in these spaces without seeing the need or added value in a VLE. Those students already enrolled on the programme for the previous two years, and so already familiar with the VLE and perhaps wanting to keep academic staff at more of a distance, may not take up such offers.

Nevertheless, the study offers a common recommendation to streamline information to all students and make sure to be as organised as possible. In particular, this means minimising timetable or location changes, communicating well in advance, and avoiding the clutter that creeps into group emails. The latest information must be prominent so that rumours or misinformation are not spread through informal channels. It must also be recognised that lecturers will need to devote some of their time to students' administrative enquiries. While full-time students may manage perfectly well with dedicated administrative staff, this seems not the case with transfer students. There is value in a single point of contact with the authority of an academic, even if it is simply to tell students what the referencing system is or how to reset a Moodle password. How to account for such tasks in a workload model could be problematic, but helping with such simple tasks may perform important relationship-building and trust-building work. Alternatively, universities may need to find ways to develop trusted single points of contacts within administrative staff who can take on such mediation roles. 


\section{References}

Boud, D., \& Molloy, E. (2013). Rethinking models of feedback for learning: The challenge of design. Assessment and Evaluation in Higher Education, 38(6), 698-712. https://doi.org/10.1080/02602938.2012.691462

Brown, A., Moerkamp, T., \& Voncken, E. (1999). Facilitating progression to higher education from vocational paths. European Journal of Education, 34(2), 219-235. https://doi.org/10.1080/01418219999449

Cheung, K., Yip, T. L., Johnny Wan, C. L., Tsang, H., Zhang, L. W., \& Parpala, A. (2020). Differences in study workload stress and its associated factors between transfer students and freshmen entrants in an Asian higher education context. PLoS ONE, 15(5). https://doi.org/10.1371/journal.pone.0233022

Connell-Smith, A., \& Hubble, S. (2018). Widening Participation strategy in HE in England. UK Parliament. https://commonslibrary.parliament.uk/research-briefings/cbp8204/\#: : text=Widening\%20participation\%20straregy\%20aims $\% 20$ to,to $\% 20$ entry $\% 20$ to $\% 20$ higher $\% 20$ education.

Curtis, D. (2009). Student transfer: At a Glance (Vol. 12, Issue 3). National Centre for Vocational Education Research https://www.ncver.edu.au/_data/assets/file/0010/2404/nd06103.pdf

Denovan, A., \& Macaskill, A. (2013). An interpretative phenomenological analysis of stress and coping in first year undergraduates. British Educational Research Journal, 39(6), 1002-1024. https://doi.org/10.1002/berj.3019

Fernandes, A., Ford, A., Rayner, G., \& Pretorius, L. (2017). Building a sense of belonging among tertiary commuter students: The Monash Non-Residential Colleges program. Student Success, 8(2), 31. https://doi.org/10.5204/ssj.v8i2.380

Foster, M. (2008). The challenge of different ways of learning for Chinese students in UK HE. In Enhancing the Experience of Chinese Students in UK Higher Education: Lessons from a Collaborative Project. Staff and Educational Development Association.

Gale, T., \& Parker, S. (2014). Navigating change: A typology of student transition in higher education. Studies in Higher Education, 39(5), 734-753. https://doi.org/10.1080/03075079.2012.721351

James, R., Krause, K., \& Jennings, C. (2009). The first year experience in Australian universities: Findings from 1994 to 2009. Centre for the Study of Higher Education. http://citeseerx.ist.psu.edu/viewdoc/download?doi=10.1.1.723.8190\&rep=rep1\&type=pdf

Kember, D. (1999). Integrating part-time study with family, work and social obligations. Studies in Higher Education, 24(1), 109-124. https://doi.org/10.1080/03075079912331380178

Kennedy, H. (1997). Learning works: Widening participation in further education. Further Education Funding Council UK. https://dera.ioe.ac.uk/15073/2/Learning\%20works\%20$\% 20$ widening\%20participation\%20in\%20further\%20education\%20\%28Kennedy\%20report\%29.pdf

Kift, S., Nelson, K., \& Clarke, J. (2010). Transition pedagogy: A third generation approach to FYE - A case study of policy and practice for the higher education sector. The International Journal of the First Year in Higher Education, 1(1), 1-20. https://doi.org/10.5204/intjfyhe.v1i1.13

Longden, B. (2006). An institutional response to changing student expectations and their impact on retention rates. Journal of Higher Education Policy and Management, 28(2), 173-187. https://doi.org/10.1080/13600800600751044

Martin, K. D., \& Murphy, P. E. (2017). The role of data privacy in marketing. Journal of the Academy of Marketing Science, 45(2), 135-155. https://doi.org/10.1007/s11747-016-0495-4

Marton, F., \& Saljo, R. (2005). Approaches to learning. In D. Hounsell (Ed.), The experience of learning: Implications for teaching and studying in higher education (3rd ed., pp. 39-58). University of Edinburgh.

Nelson, K. J., Smith, J. E., \& Clarke, J. A. (2012). Enhancing the transition of commencing students into university: An institution-wide approach. Higher Education Research and Development, 31(2), 185-199. https://doi.org/10.1080/07294360.2011.556108

Nisbet, J. B., Entwistle, N. J., McQuillin, B., \& Robinson, I. M. (2005). Staff and student perceptions of the teaching-learning environment: A case study. International Journal of Electrical Engineering Education, 42(1), 30-40. https://doi.org/10.7227/IJEEE.42.1.5

Roberts, C., \& Sarangi, S. (2001). "Like you're living two lives in one go": Negotiating different social conditions f or classroom learning in a further education context in England. In M. Heller \& M. Martin-Jones (Eds.), Voices of authority. education and linguistic difference (pp. 171-192). Ablex.

Sadler, D. R. (2010). Beyond feedback: Developing student capability in complex appraisal. Assessment and Evaluation in Higher Education, 35(5), 535-550. https://doi.org/10.1080/02602930903541015

Saldaña, J. (2013). The coding manual for qualitative researchers (3rd ed.). Sage.

Sanchez-Gelabert, A., Figueroa, M., \& Elias, M. (2017). Working whilst studying in higher education: The impact of the economic crisis on academic and labour market success. European Journal of Education, 52(2), $232-245$. https://doi.org/10.1111/ejed.12212

Smith, K., \& Hopkins, C. (2005). Great expectations: Sixth-formers' perceptions of teaching and learning in degree-level English. Arts and Humanities in Higher Education, 4(3), 304-318. https://doi.org/10.1177/1474022205056173 
Thomas, L. (2012). What works? Student retention \& success. Paul Hamlyn Foundation.

Thomas, L. (2020). Excellent outcomes for all students: A whole system approach to widening participation and student success in England. Student Success, 11(1), 1-11. https://doi.org/10.5204/ssj.v11i1.1455

Thomas, L., \& Jones, R. (2017). Student engagement in the context of commuter students. [pdf] London: The Student Engagement Partnership. www.tsep.org.uk/resources

Tucker, C. E. (2014). Social networks, personalized advertising, and privacy controls. Journal of Marketing Research, 51(5), 546-562. https://doi.org/10.1509/jmr.10.0355

Wenger, E., McDermott, R. A., \& Snyder, W. (2002). Cultivating communities of practice: A guide to managing knowledge. Harvard Business Press.

\section{Please cite this article as:}

Foster, M., Mulroy, T., \& Carver, M. (2020). Exploring coping strategies of transfer students joining universities from colleges. Student Success, 11(2), 72-81. https://doi.org/10.5204/ssj.v11i2.1617

This article has been peer reviewed and accepted for publication in Student Success. Please see the Editorial Policies under the 'About' section of the Journal website for further information.

Student Success: A journal exploring the experiences of students in tertiary education 